\title{
Pyrolysis oil combustion in a horizontal box furnace with an externally mixed nozzle
}

Frank C. Lujaji, ${ }^{\prime,+}$ Akwasi A. Boateng, ${ }^{*}{ }^{\dagger}$ Mark A. Schaffer, ${ }^{\dagger}$ Charles A. Mullen, ${ }^{\prime}$

Iddi S.N. Mkilaha, ${ }^{\ddagger}$ \& Peter L. Mtui ${ }^{\ddagger}$

${ }^{\dagger}$ USDA-ARS, Eastern Regional Research Center, 600 E. Mermaid Lane, Wyndmoor, PA 19038, USA.

Nelson Mandela African Institution of Science and Technology, P.O. Box 447, Arusha, Tanzania.

Supplementary Information 


\section{Experimental Process and Instrumentation}

Figure S1, below, is a process and instrumentation diagram (P\&ID) depicting the main process interconnecting piping and instrumentation.

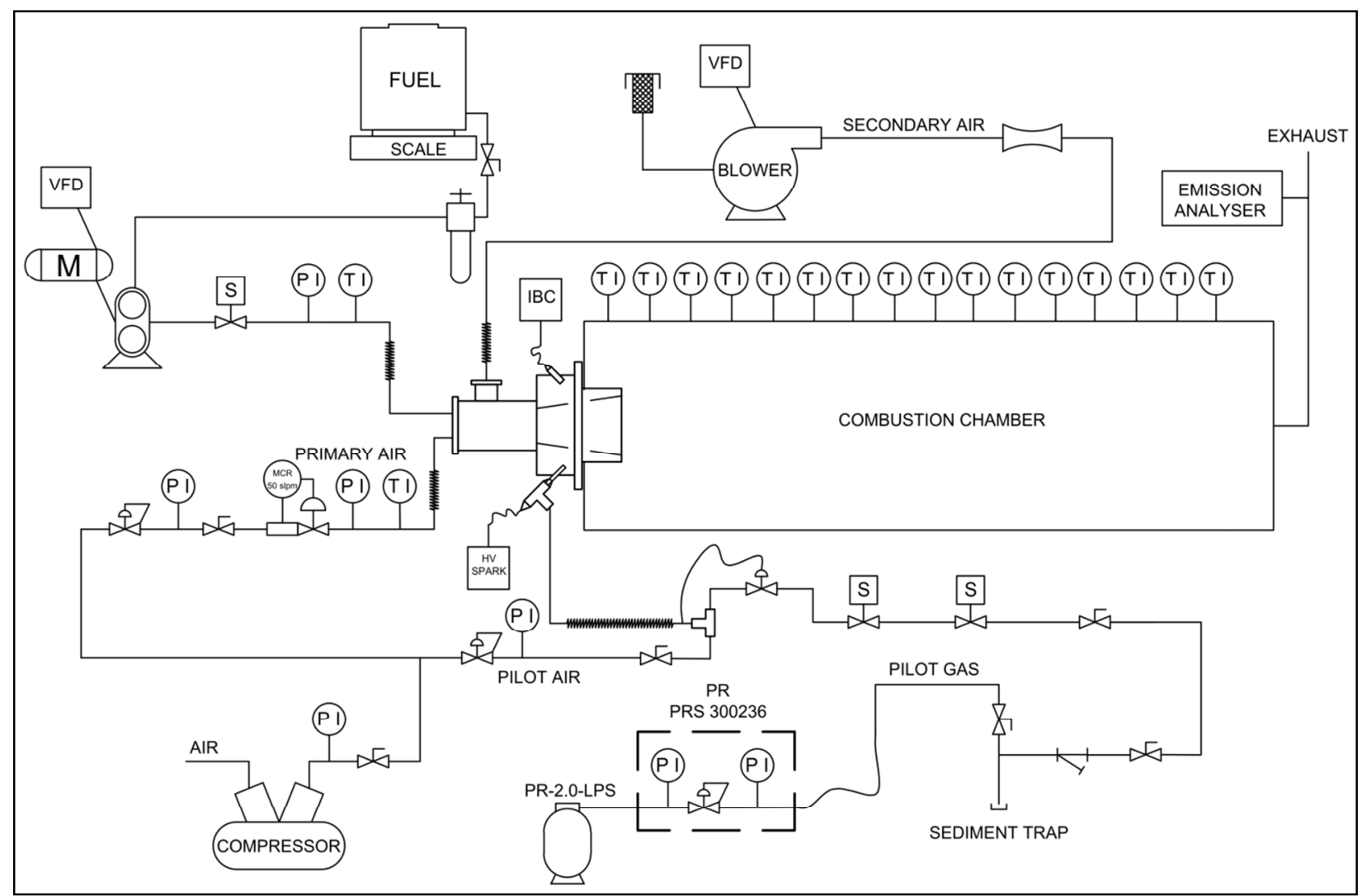

Figure S1: P\&ID of the Experimental Apparatus

Key: IBC: Integrated Burner Control

TI: Temperature Indication

VFD: Variable Frequency Drive

PI: Pressure Indication

S: Solenoid

M: Motor

\section{Fuel flow measurement}

The digital scale measuring the weight of the fuel tank communicates with a programmable logic controller (PLC) via serial ASCII over RS-232. It was set to stream continuously while the PLC receives these data and logs along with a timestamp. The PLC was programmed to calculate the difference in mass between the current scale datum and the previous scale datum. 
$\dot{m}_{i}=\frac{m_{i}-m_{i-1}}{t_{i}-t_{i-1}}$

where:

$m_{i}, m_{i-1}=$ mass in $\mathrm{kg}$ of the current and previous scale masses

$t_{i}, t_{i-1}=$ timestamp in milliseconds of the current and previous timestamps

$\dot{m}_{i}=$ instantaneous mass flowrate in $\mathrm{kg} / \mathrm{s}$ of the $i_{t h}$ data point

To reduce signal noise, a smoothing technique was employed in which moving average of 20 data points was calculated to obtain the fuel mass flowrate $\dot{m}_{f}$ (Equation 5).

$\dot{m}_{f}=\frac{1}{n} \sum_{i}^{i-20} \dot{m}_{i}$

This value of mass flowrate $\dot{m}_{f}$ in $\mathrm{kg} / \mathrm{s}$ was then logged. The desired fuel mass flowrate for a given operating condition was set by adjusting the needle valve.

\section{Data acquisition}

To set the operating parameters and record combustion experiment data, a PLC (Automation Direct DL205 base) was installed with a H2-DM1E processor, and nine thermocouple modules were used. The touch panel display was connected to the PLC, providing the human-machine interface (HMI), which was programmed to display and log data continuously every second. The PLC controlled two variable-frequency motor drives via MODBUS RTU over RS-485, which were used to control the secondary air and fuel pumping rate. The PLC was also connected to the IBC flame management system, pilot burner system, thermocouples, mass flow controller to 
control atomization flowrate. The PLC was programmed to initiate the burner start sequence and monitor different parameters. Data were saved as a text file.

\section{Emission Analyzer}

Details for the emission analyzer sensor data are shown in Table S1 below.

Table S1: Testo 350 Emission and Combustion Analyzer Sensor Descriptions

\begin{tabular}{|c|c|c|}
\hline & Measurement & \\
\hline Measurement Parameter & Range & Resolution \\
\hline $\mathrm{O}_{2}$ & 0 to 25 vol. $\%$ & 0.01 vol. $\%$ \\
\hline $\mathrm{CO}$ & 0 to $10000 \mathrm{ppm}$ & $1 \mathrm{ppm}$ \\
\hline $\mathrm{CO}_{\text {low }}$ & 0 to $500 \mathrm{ppm}$ & $0.1 \mathrm{ppm}$ \\
\hline NO & 0 to $4000 \mathrm{ppm}$ & $1 \mathrm{ppm}$ \\
\hline $\mathrm{NO}_{\text {low }}$ & 0 to $300 \mathrm{ppm}$ & $0.1 \mathrm{ppm}$ \\
\hline $\mathrm{NO}_{2}$ & 0 to $500 \mathrm{ppm}$ & $0.1 \mathrm{ppm}$ \\
\hline $\mathrm{CO}_{2}-(\mathrm{IR})$ & 0 to 50 vol. $\%$ & 0.01 vol. $\%$ ( 0 to 25 vol. $\%) ; 0.1$ vol. $\%(>25$ vol. $\%)$ \\
\hline $\mathrm{CxHy}$ & 100 to $40000 \mathrm{ppm}$ & $10 \mathrm{ppm}$ \\
\hline
\end{tabular}

\section{Spray Characteristics}

The atomized fuel droplets Reynolds number (Re) and Peclet number (Pe) were calculated by using Equations S1-S3. Equation S4 was used to estimate the theoretical Sauter Mean Diameter (SMD) for droplets from a plain-jet air-blast atomizer. ${ }^{1,2}$ The properties (specific heat capacity and thermal conductivity) for bio oil and diesel used in the calculations are shown in Table S2 below. 
$\operatorname{Re}=\frac{V_{\text {slip }} \rho_{\text {air }} d_{L}}{\mu_{\text {air }}}$

$\operatorname{Pr}=\frac{c_{p, L} \mu_{L}}{k_{L}}$

$P e=\operatorname{Pr} \cdot \operatorname{Re}$

$S M D=0.95 \cdot\left[\frac{\left(\sigma_{L} \dot{m}_{L}\right)^{0.33}}{\rho_{L}{ }^{0.37} \rho_{\text {air }}{ }^{0.3} U_{R}}\right] \cdot\left(1+\frac{\dot{m}_{L}}{\dot{m}_{\text {air }}}\right)^{1.7}+0.13 \cdot\left[\frac{\mu_{L}{ }^{2} d_{O}}{\sigma_{L} \rho_{L}}\right]^{0.5} \cdot\left(1+\frac{\dot{m}_{L}}{\dot{m}_{\text {air }}}\right)^{1.7}$

Table S2: Other fuel properties

\begin{tabular}{lccccc}
\hline Property & Units & \multicolumn{2}{c}{ Bio-oil } & \multicolumn{2}{c}{ Diesel } \\
Air-fuel equivalence ratio & - & 0.53 & 0.68 & 0.53 & 0.68 \\
\hline Sauter Mean Diameter (SMD) & {$[\mu \mathrm{m}]$} & 423.62 & 423.62 & 38.86 & 38.86 \\
Spray droplet Reynolds number (Re) & - & 1758.33 & 1769.40 & 212.76 & 213.33 \\
Spray droplet Peclet number (Pe) & - & 888.27 & 893.86 & 4.06 & 4.07 \\
Specific heat capacity & {$[\mathrm{kJ} / \mathrm{kg} \mathrm{K}]$} & $0.39 *$ & $0.39 *$ & $0.12^{* *}$ & $0.12^{* *}$ \\
Thermal conductivity & {$[\mathrm{W} / \mathrm{mK}]$} & $3.20^{*}$ & $3.20^{*}$ & $1.95^{* *}$ & $1.95^{* *}$
\end{tabular}

$*^{3} ; * *^{4}$ 


\section{Reference}

(1) Martin, J. A.; Boateng, A. A. Combustion performance of pyrolysis oil/ethanol blends in a residential-scale oil-fired boiler. Fuel 2014, 133, 34-44.

(2) Lefebvre, A. H. Airblast atomization. Prog. Energy Combust. Sci. 1980, 6, (3), 233-261.

(3) Lehto, J.; Oasmaa, A.; Solantausta, Y.; Kytö, M.; Chiaramonti, D. Fuel oil quality and combustion of fast pyrolysis bio-oils. VTT Technol. 2013, 87, 79.

(4) Guimarães, A. O.; Machado, F. A. L.; da Silva, E. C.; Mansanares, A. M. Investigating thermal properties of biodiesel/diesel mixtures using photopyroelectric technique.

Thermochim. Acta 2012, 527, 125-130. 


\section{Unit of Terms}

\section{Units of Terms}

$\rho \quad$ density $[\mathrm{kg} / \mathrm{m} 3]$

$d \quad$ diameter $[\mathrm{m}]$

$V \quad$ droplet velocity $[\mathrm{m} / \mathrm{s}]$

$\dot{m} \quad$ mass flowrate $[\mathrm{kg} / \mathrm{s}]$

$c_{\mathrm{p}} \quad$ specific heat capacity $\left[\mathrm{kJ} \mathrm{kg}^{-1} \mathrm{~K}^{-1}\right]$

$k \quad$ thermal conductivity [ $\mathrm{W} \mathrm{m} \mathrm{m}^{-1} \mathrm{~K}^{-1}$ ]

$\mu \quad$ dynamic viscosity [cP]

Pe Peclet number

PI pressure indication

Pr Pranditl number

Re Reynolds number

SMD Sauter mean diameter $[\mu \mathrm{m}]$

$U \quad$ velocity $[\mathrm{m} / \mathrm{s}]$

$\sigma \quad$ surface tension $[\mathrm{N} / \mathrm{m}]$

\section{Subscripts:}

$\begin{array}{ll}\mathrm{L} & \text { liquid } \\ \mathrm{O} & \text { orifice } \\ \mathrm{R} & \text { relative }\end{array}$

